\title{
Structural-Phase States and Wear Resistance of Surface Formed on Steel by Surfacing
}

\author{
Evgenie V. Kapralov ${ }^{1}$, Sergey V. Raykov ${ }^{1}$, Ekaterina S. Vaschuk ${ }^{1}$, \\ Yuri F. Ivanov ${ }^{2,3, a)}$, Evgenie A. Budovskikh ${ }^{1}$, and Victor E. Gromov ${ }^{1, \text { b) }}$ \\ ${ }^{1}$ Siberian State Industrial University, Novokuznetsk, 654007, Russia \\ ${ }^{2}$ Institute of High-Current Electronics SB RAS, Tomsk, 634055, Russia \\ ${ }^{3}$ National Research Tomsk Polytechnic University, Tomsk, 634050, Russia \\ a)yufi55@mail.ru \\ b) Corresponding author: gromov@physics.sibsiu.ru
}

\begin{abstract}
Investigations of elementary and phase structure, state of defect structure and tribological characteristics of a surfacing, formed on a low carbon low-alloy steel by a welding method were carried out. It was revealed that a surfacing, formed on a steel surface is accompanied by the multilayer formation, and increases the wear resistance of the layer surfacing as determined.
\end{abstract}

Keywords: steel Hardox 400, surfacing, structure, phase composition, wear resistance

\section{INTRODUCTION}

Electric arc surfacing takes strong positions in the improvement of structure of machine parts and mechanisms in different branches of industry. As a result of surfacing and in a manufacture of machine parts it is possible to obtain a working surface possessing a necessary complex of properties: wear resistance, heat stability, heat resistance, corrosion resistance, etc. Using a surfacing, it is possible to reduce the consumption of the expensive nonferrous metals, alloys and high carbon steels. Besides, repeated restoration of the worn parts decreases to a large extent the consumption of metal for the manufacture of spare parts of the equipment. The increase of service life of equipment parts is especially important, if the performance of high efficient equipment depends on their reliability and durability. A high economical and technical efficiency of surfacing in metallurgical machine building is specified by it. The efficiency of structure improvement by surfacing is determined by the right choice of deposited metal composition, based on the conditions of work of a part and a main type of wear. The choice of the deposited material is done with regard to exploitation conditions of the part being restored, type of protection, design features of a part and the equipment available. At present a large number of electrode materials has been developed on the base of iron for arc surfacing.

\section{MATERIAL AND RESEARCH METHOD}

Steel Hardox 400 was used as a test material; its element composition is shown in Table 1. Thick deposited layers (3-5 $\mathrm{mm}$ in thickness) were formed on the steel surface by welding method. The investigation of element and phase composition, state of defect substructure of deposited layer were done by the methods of optic (metallographic micro-visor $\mu$ Vizo-MET-221), scanning (scanning electron microscope Philips SEM-515 with microanalyzer EDAX ECON IV) and X-ray structural analysis (X-ray diffractometer DRON-7). Tribological characteristics of coating were revealed by wear resistance and friction coefficient determination (tribotester Tribotechnic).

International Conference on Physical Mesomechanics of Multilevel Systems 2014

AIP Conf. Proc. 1623, 233-236 (2014); doi: 10.1063/1.4898925

(C) 2014 AIP Publishing LLC 978-0-7354-1260-6/\$30.00 

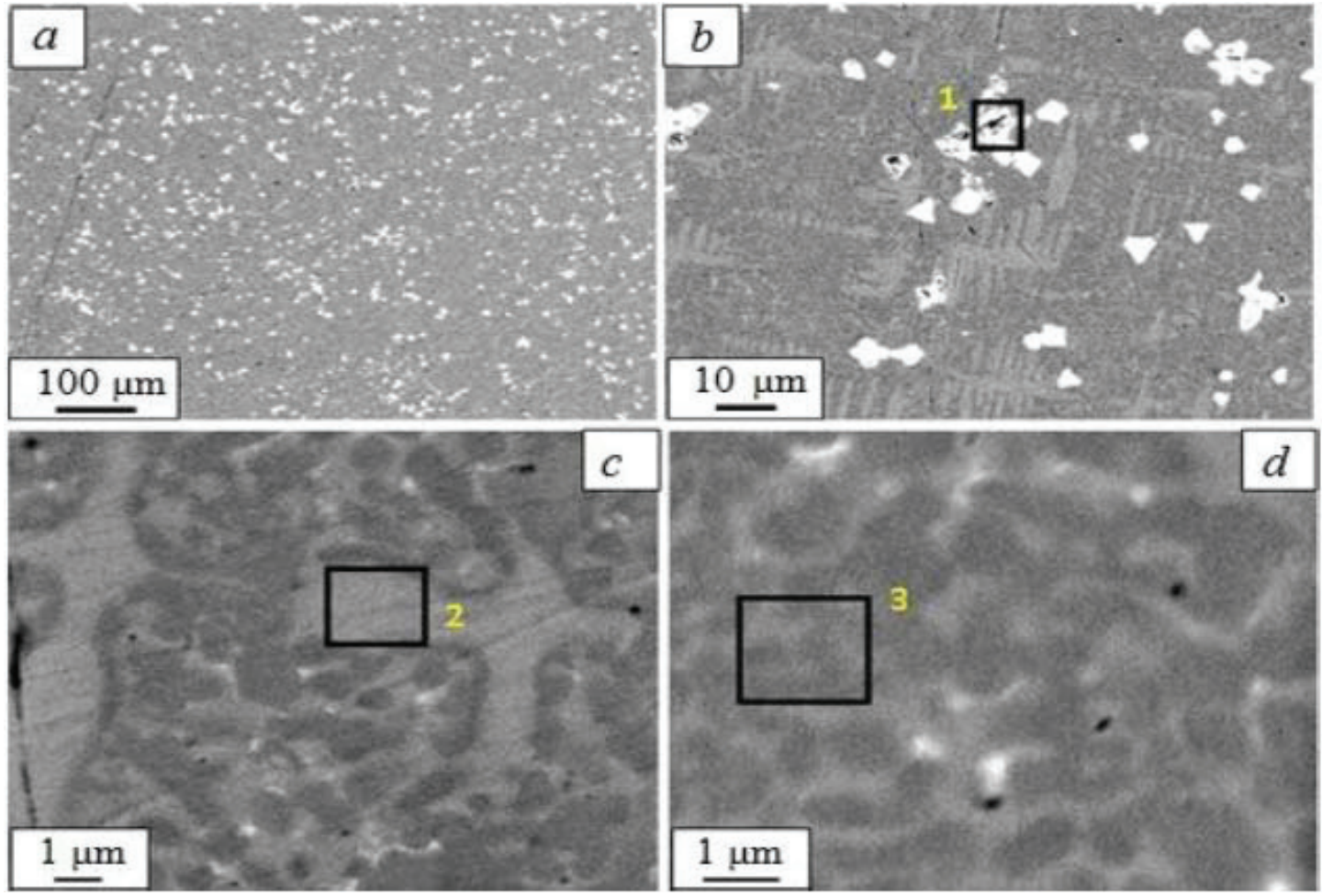

FIGURE 1. Structure of surfacing being formed on the surface of steel. Section is parallel to the surface of surfacing. Frames show the sites of X-ray spectrum analysis of the material

Tribological tests were done under the following conditions: a ball with diameter of $3 \mathrm{~mm}$ from a hard alloy VK8 was used as a counterbody. A counterbody was shifted on the sample surface along the circle of $4 \mathrm{~mm}$ diameter at linear velocity $2 \mathrm{~cm} / \mathrm{s}$ under normal load $5 \mathrm{~N}$. The total number of revolutions of counterbody was 5000 .

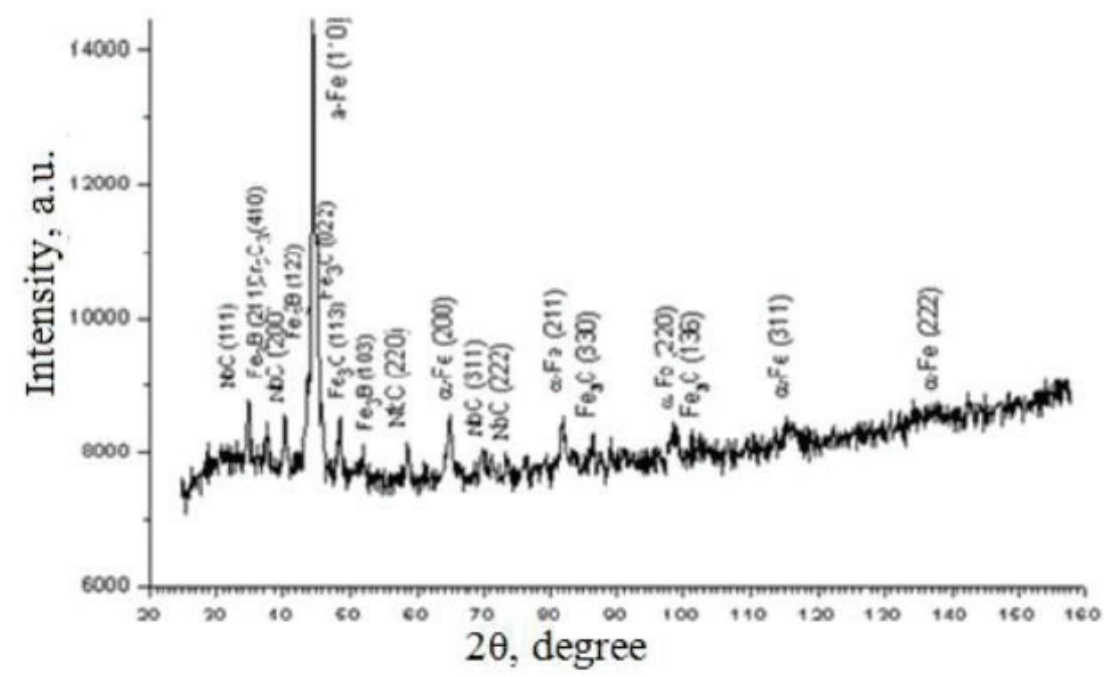

FIGURE 2. Part of of X-ray diffraction pattern obtained from the surface layer of surfacing 


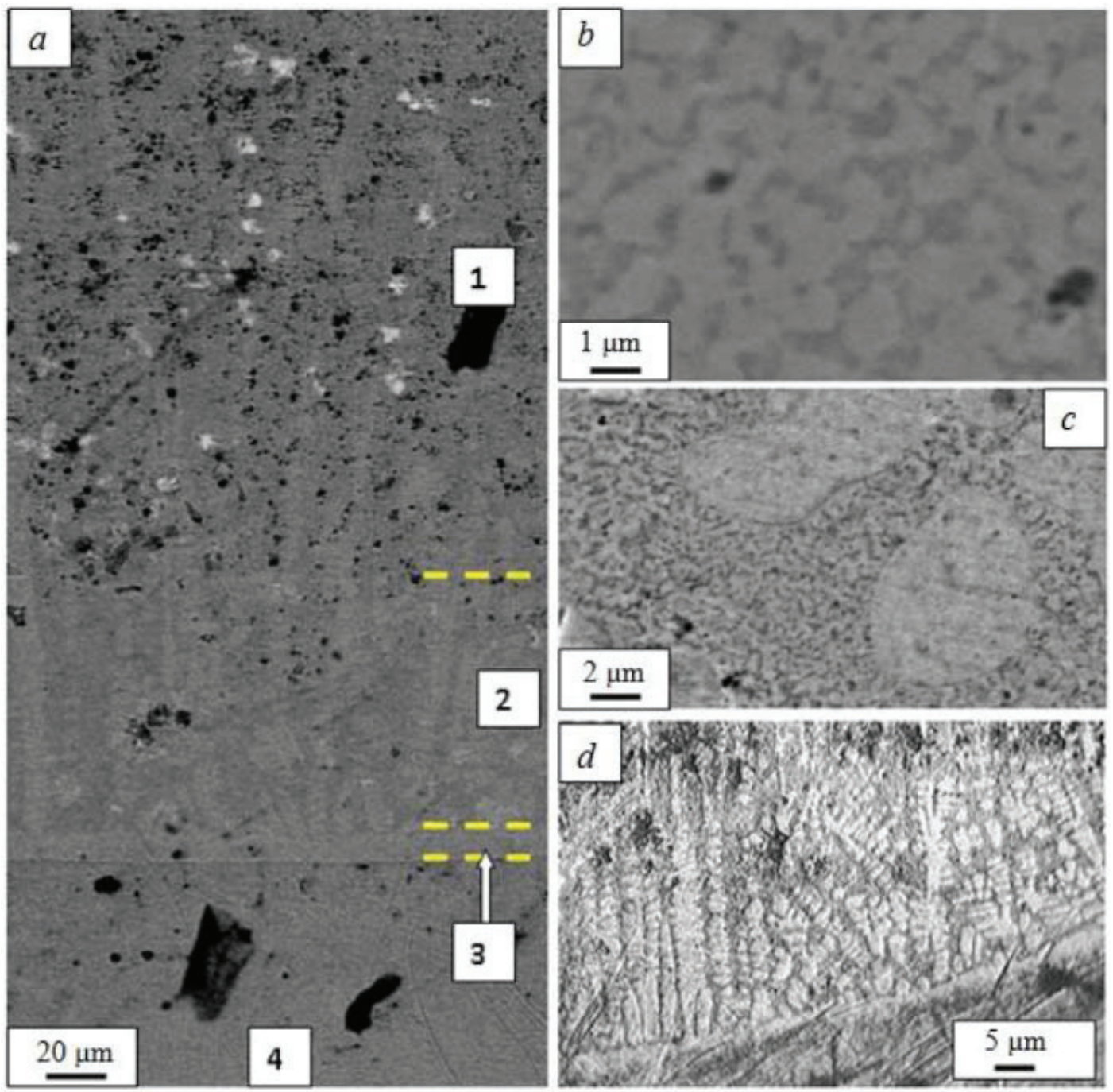

FIGURE 3. Structure of transversal metallographic section of surfacing, formed on steel. Designation: 1 - surfacing layer; 2, 3-transition layers; 4-layer of thermal influence of steel; (b) structure of zone 1; (c) zone 2; (d) zone 3

\section{RESULTS OF INVESTIGATIONS AND DISCUSSION}

The tribological test has shown that the formation of surfacing on the surface of steel Hardox 400 results in the increase of wear resistance of material surface layer by a factor of $\sim 2.25$ and decrease of friction coefficient-by a factor of -1.05 .

To establish the physical mechanisms of wear resistance increase of steel with deposited material the studies of structure, phase and element composition of surfacing steel system were carried out. Structure and element composition analyses were done in two sections: in section parallel to the surface of surfacing and in section perpendicular to the deposited layer.

The structure of surfacing is shown in Fig. 1. A large number of inclusions are of edged shape. Inclusion sizes vary within 1 to $5 \mu \mathrm{m}$. The second morphological element of the deposited layer is a structure of dendritic (Fig. 1(b, c)) and cellular (Fig. 1(c, d)) crystallization. The cell sizes vary within 0.3 to $0.8 \mu \mathrm{m}$. The cells are separated by interlayers of 50 to $100 \mathrm{~nm}$ thickness. 
X-ray spectral analysis of surfacing sites, designated by frame in Fig. 1, has shown that particles of the edged shape are enriched by atoms of niobium (Fig. 1(b), zone 1); zones of dendritic crystallization (Fig. 1(c), zone 2) are enriched by atoms of iron, chromium and carbon. A characteristic feature of the cellular crystallization structure being formed largely by atoms of iron is the presence of carbon and chromium atoms of large concentration (Fig. 1(c), zone 3).

Phase composition of surface surfacing layer was analyzed by X-ray diffraction method. X-ray diffraction pattern obtained from the surface surfacing layer is shown in Fig. 2. When analyzing the results shown it can be noted that the basic phase of the tested surfacing is $\alpha$-iron, the average size of coherent scattering zone of which is $D=30 \mathrm{~nm}$. The revealed parameter of $\alpha$-iron crystal lattice is somewhat higher than that of $\alpha$-iron containing no admixture $\left(a_{0}=0.28668 \mathrm{~nm}\right.$ [1]). Suppose the increase of crystal lattice parameter of surfacing $\alpha$-phase is caused by formation of solid solution oversaturated by carbon atoms. In this case, using the estimation expression, given in [2, $3]$, it can be shown that carbon concentration located in crystal lattice on the base of $\alpha$-iron is $0.018 \%$ wt.

Phase composition is represented by a second phase particles: by particles of iron carbide of composition $\mathrm{Fe}_{3} \mathrm{C}$ (cementite), the volume fraction of which is $10 \%$, of niobium and chromium carbides $\mathrm{NbC}$ and $\mathrm{Cr}_{3} \mathrm{C}_{2}$ (sum volume fraction of carbides is $20 \%$ ) and of boride of iron $\mathrm{Fe}_{3} \mathrm{~B}$, the volume fraction of which is $10 \%$.

Cross-section analysis of surfacing substrate system made it possible to reveal the multilayer structure which according to morphological characteristics can be presented by surfacing layer (Fig. 3(a), layer 1), transition layers (Fig. 3(a), layers 2 and 3) and a layer of thermal transformation of steel (Fig. 3, layer 4). Surfacing layer (Fig. 3, layer 1) has principally a structure of cellular crystallization and is characterized by the presence of particles, enriched by niobium (Fig. 3(a, b)). Sizes of crystallization cells vary within 0.5 to $1.0 \mu \mathrm{m}$; a thickness of interlayers separating them is $0.1-0.3 \mu \mathrm{m}$.

The first transition layer (Fig. 3, layer 2) has an island-type structure. Islands of sizes 5-10 $\mu \mathrm{m}$ are separated by extended interlayers having a complex substructure, the element sizes of which vary within 300-600 nm (Fig. 3C). The second transition layer, directly adjacent to steel interface is comparatively thin 10-20 $\mu \mathrm{m}$ and is characterized by column dendritic structure being formed from the steel interface (Fig. 3(d)). In specific cases, microcracks and comparatively large $0.9-1.0 \mu \mathrm{m}$ second phase precipitates are located along the interface of layers 2 and 3 .

\section{SUMMARY}

The carried out studies of structure, element and phase composition of surfacing formed on the low carbon lowalloyed steel Hardox 400 make it possible to make the following conclusion:

1. Formation of surfacing on the surface of steel is accompanied by the formation of multi-layer structure, the layer of which differs in the morphology of element substructure.

2. Surfacing is a multi-phase material and is presented by solid solution grains on the basis of $\alpha$-iron, by particles of iron carbide of composition $\mathrm{Fe}_{3} \mathrm{C}$ (cementite), the volume fraction of which is $10 \%$, of niobium and chromium carbides $\mathrm{NbC}$ and $\mathrm{Cr}_{3} \mathrm{C}_{2}$ (sum volume fraction of carbides is $20 \%$ ) and of boride of iron $\mathrm{Fe} 3 \mathrm{~B}$, the volume fraction of which is $10 \%$.

3. The revealed multiple (more then twice) increase of wear resistance of deposited layer (para to volume of steel) is specified by formation of submicro- and nanosize structure of $\alpha$-phase crystallization and precipitation of large volume $(\sim 40 \%)$ of particles of high strength of carbide and boride phases.

\section{ACKNOWLEDGEMENT}

This work was supported in part by the Russian Foundation for Basic Research (Scientific Project No. 13-0212009 ofi_m) and by the Ministry of Education and Science of the Russian Federation State Assignment 2708 G3.

\section{REFERENCES}

1. A. P. Babichev, N. S. Babushkin, A. M. Bratkovskii, et al., Physical Values (Energoatomizdat, Moscow, 1991).

2. V. G. Kurdyumov, L. M. Utevskii, and R. I. Entin, Transformation in Iron and Steel (Nauka, Moscow, 1977).

3. E. J. Fasiska and H. Wagenblat, Trans. Met. Soc. AIME 11, 1818 (1967). 